cause mesovarian leiomyomas or any other kind of tumour in human beings.

During November the Pulmonary, Allergy and Clinical Immunology Advisory Committee of the US Food and Drug Administration considered the special report on salbutamol and other evidence at an open meeting in Washington and recommended, in essence, that the status quo concerning $\beta$-stimulant bronchodilators in the USA should be maintained and that, in order to clarify the toxicological position, long-term studies should be carried out in higher species, and especially in monkeys, on the $\beta$-stimulants currently marketed in the USA as well as those at the developmen stage. The effect of this recommendation on salbutamol in that country is that clinical trials will remain suspended until the new toxicity test requirements have been met.

A diffuse, largely inexpert, discussion of possible drug-induced lesions in the rat other than mesovarian leiomyomas also took place at the November meeting. As a result, we sent an addendum to the special report to the advisory committee and to all national drug authorities in order to present the opinions of the experts who were intimately involved with the long-term Schering rat studies, opinions which were not adequately presented at the open meeting. These opinions make clear the nature and significance of the other lesions found in the rats and accord with their conclusion that no tumours other than mesovarian leiomyomas occurred with toxicologically significant frequency.

Mesovarian leiomyomas are extremely rare in human beings and any substantial increase in their incidence which resulted from the use of adrenergic drugs would be obvious because the ovaries are regularly examined during common gynaecological operations. There is no evidence to suggest that the systemic use of adrenergic drugs, which started with ephedrine about 50 years ago in western countries, has had any effect on the incidence of smooth-muscle tumours in women. No such lesions have been reported in association with treatment with orciprenaline, which has been used for more than 15 years, or with salbutamol or terbutaline, which have been extensively used for nearly 10 years. This is, of course, the expected resul because human beings are never regularly exposed to the intensity of $\beta$-adrenergic challenge to which all the treated rats were exposed in the oncogenic studies. The cardiovascular effects and muscle tremor which would accompany the use of such high doses of $\beta$-stimulants in man would be intolerable.

Having considered all the evidence, we have offered the following advice to Glaxo Group companies :

(1) There is no evidence that the therapeutic use of salbutamol-containing preparations, by inhalation or by mouth, for nearly 10 years has resulted in an increase in tumours of any kind or in any other serious drug-induced side effect in patients.

(2) There is no good reason for supposing that the therapeutic use of salbutamol will cause mesovarian leiomyomas or any other kind of tumour in human beings because rats, the only known sensitive species, are known to respond aberrantly in other ways to $\beta$-stimulants and because, given the pharmacological nature of $\beta$-stimulant drugs, human beings have never been and never will be subjected to prolonged intense systemic $\beta$-stimulation.

(3) There is no evidence that salbutamol is carcinogenic in any species and much evidence that it is most unlikely to be so.

(4) Salbutamol, the first highly selective $\beta_{2}$-adrenergic bronchodilator, is a valuable drug in the management of bronchial asthma; there is no rational basis for discontinuing its use.

D POYNTER

D M HARRIS

DAVID JACK
' Nelson, L W, and Kelly, W A, Veterinary Pathology, Nelson, L W, Kelly, W A, and Werkel, J H, Toxi-
cology and Applied Pharmacology, 1972, 23, 731 .

\section{Schistosomiasis in China}

SIR,-I thought your leading article on schistosomiasis in China (19 November, p 1304) very timely, but it contains several misconceptions.

Reduction in the incidence of schistosomiasis in China is a clear manifestation of the ideology underlying the Chinese health delivery system. An attack on snails was initiated only after prolonged discussion between medical experts and the equally important peasant experts. The parasitologists defined the life cycle and vulnerability of the fluke and this was their contribution. The peasants, with their intimate knowledge of irrigation, could suggest how the enormous practical problems of digging in the snails might be overcome. It is because of this combined approach involving many groups of people that mass mobilisation was possible.

Your reference to "a striking disregard for or nonchalance about" these labour demands reflects the general misconception prevalent in the West that these mass campaigns, so successful in China, are imposed on people. What the Chinese have shown is that when ordinary people are given responsibility for their own health they respond with a commitment and positive attitude that does make light of the problems which confront them, and it is this essential ingredient which you have failed to take note of in your article.

I think the fact that the Chinese are the only nation in the world to reduce schistosomiasis radically in their country testifies to the effective manner in which mass health campaigns can advance a nation's health. Your article does not sufficiently stress that point either.

Lewisham Hospital,

London SE13

\section{Life with spina bifida}

SIR,-As a parent of a child who had spina bifida I was most interested in the article by Professor R B Zachary (3 December, p 1460) concerning "Life with spina bifida" and his discussion of the controversy around attitudes in management: "Should they be allowed to die?".

It seems extremely sad that the proposal that those children who would naturally die at an early age should be allowed to do so rather than have to suffer the trauma of such a series of operations as is described in Professor Zachary's first section should be misinterpreted by those managing the care of those children in hospital. It is indeed horrifying that doctors should deliberately administer drugs to hasten the death of a child. Yet it is not altogether surprising. With the development of drugs which will prolong life unnaturally (keeping going worn-out bodies) and of those which will hasten death, suppressing vital energy, the medical profession faces the increasing dilemma of "playing God." Surely the only answer to this dilemma is to turn to God himself, who alone has the right to give and take away life.
I feel that part of this whole problem is the widespread acceptance of the premise that "their parents should not have the burden of looking after them." When the burden of responsibility is shifted from the parents to the hospital a strain is imposed on the already overstretched financial and staffing resources which leads to the exploration of every avenue for the relief of that strain, be it ethical or not. The result is effectively euthanasia-an effective if unethical means of reducing the problem.

The parent has the natural God-given advantage of maternal or paternal love. By God's grace and with the help of the medical profession the parents can give to a child afflicted with spina bifida the best possible care at home. I believe that many more parents than those who do so at present would opt to do this if the true facts of the case were laid before them. Unfortunately many parents stand in awe of hospital doctors and accept their advice as law and do not take the opportunity to make their own decision. Perhaps too many doctors underestimate the decisionmaking ability and potential for loving response to great demands that lies in parents.

My husband and I were thankful that when our son was born with spina bifida (I suppose he would have fallen into Professor Zachary's category 3, grade 3, or perhaps category 2) we were immediately given as full a picture as possible of the prognosis as far as it could be determined and the alternative courses of management. We opted to allow our child to live and die as naturally as possible, submitting him to no surgical trauma other than that which would relieve his discomfort. Although no one suggested that we should take him home, it seemed strange to us that the assumption apparently was that he should stay in hospital and we took him home as quickly as possible, six days after my caesarean section. So far as we were concerned he was simply our baby and our management of him was exactly as it would have been for any other baby, apart from the minor additional task of changing his dressing. He did not seem to suffer pain or sleeplessness that would have warranted the use of any sedative. For a time he was a brighteyed, responsive baby that would have rejoiced any mother's heart. I recognise that some parents have to face increasing problems as the child grows older. Our child lived only 11 weeks, but I had at my disposal all God's resources to cope with those 11 weeks and believe they would have still been available whatever problems I would have faced had he lived longer. Our son thrived for the first few weeks. He was a great delight to us and when he died in the way and at the time that God appointed we had the satisfaction of knowing that we had done everything we could for him. I know that not all parents have the relationship with God that we enjoy. I know that not all general practitioners are prepared to give the unfailing help, support, and encouragement that our GP gave us. Yet I believe that many more parents are able to care for and enjoy their children with spina bifida, even when very severely affected, than at present do so. We need to rethink our welfare-state attitudes and doctors must encourage parents in assuming their responsibilities instead of taking over the rights and responsibilities of both parents and God.

JANE MELton 